\title{
Risk of community-acquired pneumonia in
} chronic obstructive pulmonary disease stratified
by smoking status: a population-based cohort
study in the United Kingdom

\author{
This article was published in the following Dove Press journal: \\ International Journal of COPD \\ 14 August 2017 \\ Number of times this article has been viewed
}

\author{
Dionne CW Braeken ${ }^{1-3}$ \\ Gernot GU Rohde ${ }^{2}$ \\ Frits ME Franssen ${ }^{1,2}$ \\ Johanna HM Driessen ${ }^{3-5}$ \\ Tjeerd $\mathrm{P}$ van Staa ${ }^{3,6}$ \\ Patrick C Souverein ${ }^{3}$ \\ Emiel FM Wouters ${ }^{1,2}$ \\ Frank de Vries ${ }^{3,4,7}$ \\ 'Department of Research and \\ Education, CIRO, Horn, ${ }^{2}$ Department \\ of Respiratory Medicine, Maastricht \\ University Medical Centre \\ (MUMC+), Maastricht, ${ }^{3}$ Division of \\ Pharmacoepidemiology and Clinical \\ Pharmacology, Utrecht Institute \\ of Pharmaceutical Sciences, Utrecht, \\ ${ }^{4}$ Department of Clinical Pharmacy \\ and Toxicology, Maastricht University \\ Medical Centre (MUMC+), Maastricht, \\ ${ }^{5}$ Department of Epidemiology, \\ Care and Public Health Research \\ Institute (CAPHRI), Maastricht, \\ the Netherlands; ${ }^{6}$ Department of \\ Health eResearch, University of \\ Manchester, Manchester, ${ }^{7}$ MRC \\ Lifecourse Epidemiology Unit, \\ Southampton General Hospital, \\ Southampton, UK
}

Correspondence: Frank de Vries Division of Pharmacoepidemiology and Clinical Pharmacology, Utrecht Institute for Pharmaceutical Sciences, Utrecht University, PO Box 80082, 3508 TB

Utrecht, the Netherlands

$\mathrm{Tel}+3 \mathrm{I} 302537324$

Fax +3I 302539166

Email f.devries@uu.nl
Background: Smoking increases the risk of community-acquired pneumonia (CAP) and is associated with the development of COPD. Until now, it is unclear whether CAP in COPD is due to smoking-related effects, or due to COPD pathophysiology itself.

Objective: To evaluate the association between COPD and CAP by smoking status.

Methods: In total, 62,621 COPD and 191,654 control subjects, matched by year of birth, gender and primary care practice, were extracted from the Clinical Practice Research Datalink (2005-2014). Incidence rates (IRs) were estimated by dividing the total number of CAP cases by the cumulative person-time at risk. Time-varying Cox proportional hazard models were used to estimate the hazard ratios (HRs) for CAP in COPD patients versus controls. HRs of CAP by smoking status were calculated by stratified analyses in COPD patients versus controls and within both subgroups with never smoking as reference.

Results: IRs of CAP in COPD patients (32.00/1,000 person-years) and controls $(6.75 / 1,000$ person-years) increased with age and female gender. The risk of CAP in COPD patients was higher than in controls (HR 4.51, 95\% CI: 4.27-4.77). Current smoking COPD patients had comparable CAP risk (HR 0.92, 95\% CI: 0.82-1.02) as never smoking COPD patients (reference), whereas current smoking controls had a higher risk (HR 1.23, 95\% CI: 1.13-1.34) compared to never smoking controls.

Conclusion: COPD patients have a fourfold increased risk to develop CAP, independent of smoking status. Identification of factors related with the increased risk of CAP in COPD is warranted, in order to improve the management of patients at risk.

Keywords: COPD, respiratory infections, incidence, smoking risk

\section{Introduction}

Community-acquired pneumonia (CAP) is characterized by an acute infection of the pulmonary parenchyma with onset in the out-of-hospital setting. ${ }^{1}$ CAP incidence increases with age, smoking and the presence of comorbidities, ${ }^{1,2}$ varying between 1.5 and 11.0 per thousand adult population. ${ }^{3,4}$ In COPD, high incidence rates (IRs) of CAP, up to 22.4 per 1000 person-years, have been reported. ${ }^{5}$ Worse outcomes ie, higher mortality rates ${ }^{6,7}$ and longer length of hospital stay ${ }^{6}$ were observed, as well as more pronounced hypoxemia, ${ }^{7}$ hypercapnia, ${ }^{6,7}$ tachypnea ${ }^{6}$ and increased symptoms such as dyspnea and purulent sputum. ${ }^{7}$

Smoking individuals have a twofold increased CAP risk. ${ }^{1,4}$ Besides, smoking has been associated with increased susceptibility to infections in healthy subjects ${ }^{8}$ and 
COPD patients, triggering exacerbations. ${ }^{9}$ Until now, it is unclear whether CAP development in COPD is due to smokingrelated increased susceptibility to infections, or due to COPD pathophysiology itself. Müllerova et $\mathrm{al}^{5}$ observed no association between current smoking and CAP incidence in COPD.

As smoking has been identified as a risk factor for both COPD and CAP, it is important to compare COPD patients to smoking and nonsmoking controls, to assess smokingrelated effects, and distinguish possibly from additional risks associated with COPD and its pathophysiology. Particularly, it is important to take changes in smoking status over time into account, since smokers are known to undertake several attempts to quit smoking. ${ }^{10,11}$ Therefore, the aim of the present study was to evaluate the association between COPD and CAP by smoking status.

\section{Methods}

\section{Source population}

A population-based cohort study, with data derived from the world's largest primary care database, Clinical Practice Research Datalink (CPRD), was conducted. CPRD contains computerized medical records of 674 primary care practices in the UK, collected since January 1987, representative for the total population. ${ }^{12}$ Coded data are collected on demographics, prescription details, clinical events, preventive care provided, tests, immunizations, specialist referrals, hospital admissions, discharge summaries and details regarding death. ${ }^{12}$ The period of data collection for the present study included the period in which the quality and outcomes framework (QOF) was effective (January 2005-January 2014). ${ }^{13}$ CPRD data have been widely used to study CAP,${ }^{14,15} \mathrm{COPD}^{16,17}$ and other respiratory diseases. ${ }^{18,19} \mathrm{CPRD}$ data have been shown to be accurate and valid. ${ }^{20}$

\section{Study population}

Two cohorts were extracted. Cohort I: patients aged $\geq 40$ years with a first ever recorded COPD read code, assigned by the general practitioner (see Supplementary materials, Table S1). COPD diagnosis defined start of follow-up (index date). Cohort II: randomly selected controls, without COPD diagnosis, matched by year of birth, gender and practice, using incidence density sampling. Controls were assigned the index date of their matched COPD patient. Controls with lung medication or lung function with Tiffenau index $<0.7$ before start of follow-up were excluded. ${ }^{21}$ From both cohorts, individuals with history of asthma, history of pneumonia 3 months prior to index date, active tuberculosis or use of tuberculosis medication and unknown smoking status were excluded.

\section{Outcome}

The primary outcome was physician-recorded pneumonia diagnosis, identified by read codes (Table S2). All patients were followed from index date to end of data collection, date of transfer out of the practice, patient's death or outcome of interest, whichever came first. Follow-up time was divided into fixed intervals of 90 days.

\section{Exposure of interest}

Smoking status was determined prior to each interval (90-day) and stratified into three subcategories: never, current and former smoking. Smoking was defined by read codes (Table S3), which have provided valid estimates for the prevalence of current and never smoking. ${ }^{22}$ When the most recent smoking status was "never", and the patient had quit smoking, his status was classified as former smoking.

\section{Potential confounders}

Potential confounders were time-dependently assessed, except for gender and body mass index (BMI). Timedependent potential confounders were collected at the start of each time interval (90-day): age, history of pneumonia, cerebrovascular disease, dementia, malignancy (excluding nonmelanoma skin cancer), chronic renal disease, diabetes mellitus (use of insulin and/or blood glucose lowering medicines), cardiovascular diseases (heart failure, ischemic heart disease, coronary artery disease, myocardial infarction) and chronic liver disease. Moreover, proxies of the underlying severity of COPD, including number of exacerbations in the year before, and use of the following drugs 6 months before, were collected: short-acting beta- 2 agonists, long-acting beta-2 agonists, inhaled corticosteroids, xanthine derivatives, short-acting inhaled anticholinergics, long-acting anticholinergics, cromoglycates, oxygen or systemic glucocorticoids. ${ }^{23}$ Analyses were adjusted for exposure to antipsychotics, acid suppressants or immunosuppressants in the past 6 months, as well as influenza or pneumococcal vaccination the year before. The most recent forced expiratory volume in 1 second $\left(\mathrm{FEV}_{1}\right)$, forced vital capacity $(\mathrm{FVC})$ and Tiffenau index (ratio $\mathrm{FEV}_{1} / \mathrm{FVC}$ ) were reviewed in the time frame ever before.

\section{Statistical analysis}

Data analyses were performed using SAS 9.3. IRs were estimated by dividing the total number of CAP cases by cumulative person-time at risk. Cox proportional hazard models estimated hazard ratios (HRs) of CAP in COPD patients versus controls. Analyses were stratified to gender, age and smoking status during follow-up. 
Determinants of CAP within COPD were evaluated during follow-up: age, gender, smoking status and most recently recorded $\mathrm{FEV}_{1}$. HRs were estimated within each smoking status stratified for most recent level of airflow obstruction. HRs of CAP stratified by time-varying smoking status were assessed within COPD patients and controls separately. Never smoking was used as reference.

All analyses used time-varying Cox regression analysis. HRs were adjusted for gender and time-varying age and potential confounders (specified in previous section). Confounders were entered into the final model when independently changing the beta coefficient for current smoking by at least $5 \%$, or when consensus was reached within the research team, supported by clinical evidence from literature. A test of interaction was performed to compare effects between the defined stratifications. ${ }^{24}$ The study protocol was approved by Independent Scientific Advisory Committee, 14_055.

\section{Results}

In total, 254,277 subjects were included in the present analysis (Figure 1). Of these, 62,621 had COPD. Table 1 describes baseline characteristics: almost half were female, mean age was 67 years, follow-up time on average was 3.6-4.0 years. At baseline, smoking status differed: COPD patients were frequently former or current smokers, while controls were more often never smokers. $\mathrm{FEV}_{1}$ data were available for $<50 \%$ of COPD patients, most classified as mild-to-moderate airflow obstruction.

\section{CAP incidence}

Around $3.04 \%(n=7,730)$ of the total population was diagnosed with CAP during follow-up: 3,819 (6.10\%) COPD patients and 3,911 (2.04\%) controls. Table S4 shows IRs of CAP in COPD patients (32.00 per 1000 person-years) and controls ( 6.75 per 1000 person-years). IRs increased with age

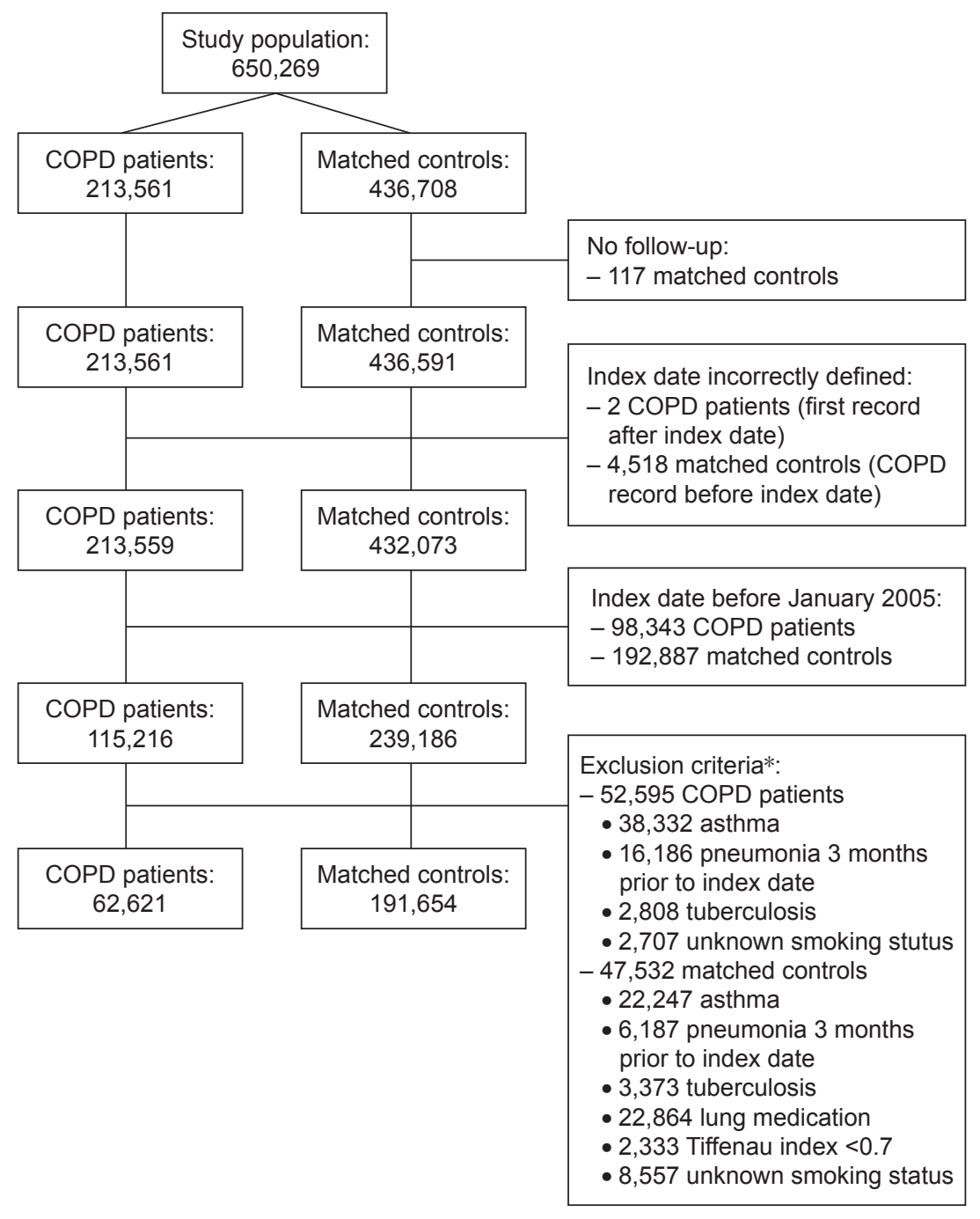

Figure I Flow chart.

Note: *Subjects can have more than one exclusion criteria. 
Table I Baseline characteristics of patients with COPD and matched controls

\begin{tabular}{|c|c|c|}
\hline Characteristics & $\begin{array}{l}\text { COPD } \\
\text { patients, } \\
\mathrm{N}=62,621\end{array}$ & $\begin{array}{l}\text { Matched } \\
\text { controls, } \\
\mathrm{N}=|9|, 654\end{array}$ \\
\hline Mean follow-up time (years) & $3.6 \pm 2.5$ & $4.0 \pm 2.5$ \\
\hline Females & $28,044(44.8)$ & $91,511(47.8)$ \\
\hline Age at index date (years) & $67.8 \pm 11.2$ & $67.4 \pm 11.5$ \\
\hline $\mathrm{BMl}$ at index date $\left(\mathrm{kg} / \mathrm{m}^{2}\right)$ & $26.8 \pm 6.0$ & $27.3 \pm 5.2$ \\
\hline Underweight (BMI $<18.5 \mathrm{~kg} / \mathrm{m}^{2}$ ) & $3,335(5.3)$ & $2,998(1.6)$ \\
\hline $\begin{array}{l}\text { Normal weight (BMI I } 8.5 \\
\text { to }<25 \mathrm{~kg} / \mathrm{m}^{2} \text { ) }\end{array}$ & $21,513(34.4)$ & $59,054(30.8)$ \\
\hline Overweight (BMI 25 to $<30 \mathrm{~kg} / \mathrm{m}^{2}$ ) & $19,649(31.4)$ & $71,236(37.2)$ \\
\hline Obese $\left(\mathrm{BMI} \geq 30 \mathrm{~kg} / \mathrm{m}^{2}\right)$ & I5,927 (25.4) & $45,481(23.7)$ \\
\hline Unknown & $2,197(3.5)$ & $12,887(6.7)$ \\
\hline \multicolumn{3}{|l|}{ Smoking status at index date } \\
\hline Never & $7,033(11.2)$ & $100,987(52.7)$ \\
\hline Current & $30,938(49.4)$ & $36,989(19.3)$ \\
\hline Former & $24,650(39.4)$ & $53,680(28.0)$ \\
\hline \multicolumn{3}{|l|}{ Drug use ( $<6$ months) } \\
\hline SABAs & $27,001(43.1)$ & 0 \\
\hline LABAs & $10,022(16.0)$ & 0 \\
\hline SAMAs & $4,607(7.4)$ & 0 \\
\hline LAMAs & $6,308(10.1)$ & 0 \\
\hline ICS & $|3| ,48(2 \mid .0)$ & 0 \\
\hline Systemic glucocorticoids & $8,850(\mid 4.1)$ & 0 \\
\hline Xanthine derivatives & $417(0.7)$ & 0 \\
\hline Oxygen & $239(0.4)$ & 0 \\
\hline Antipsychotics & $684(\mathrm{I} . \mathrm{I})$ & $\mathrm{I}, 368(0.7)$ \\
\hline Acid suppressants & $|8,63|(29.8)$ & $36,640(19.1)$ \\
\hline Immunosuppressants & $264(0.4)$ & $291(0.2)$ \\
\hline Influenza vaccination & $6,093(9.7)$ & I7,088 (8.9) \\
\hline Pneumococcal vaccination & $\mathrm{I}, 052(\mathrm{I} .7)$ & $2,707(\mathrm{I} .4)$ \\
\hline \multicolumn{3}{|l|}{ History of comorbidities } \\
\hline Coronary artery disease ${ }^{a}$ & II,I87 (I7.9) & 22,779 (II.9) \\
\hline Heart failure & $2,|7|(3.5)$ & $2,768(\mathrm{I} .4)$ \\
\hline Diabetes mellitus & $5,039(8.1)$ & $15,908(8.3)$ \\
\hline Cerebrovascular disease & $4,113(6.6)$ & $9,290(4.9)$ \\
\hline Dementia & $910(1.5)$ & $3,355(1.8)$ \\
\hline $\begin{array}{l}\text { Malignancy (excluding nonmelanoma } \\
\text { skin cancer) }\end{array}$ & $9,068(14.5)$ & $26,350(13.8)$ \\
\hline Chronic renal disease & $646(1.0)$ & $\mathrm{I}, 522(0.8)$ \\
\hline Chronic liver disease & $231(0.4)$ & $288(0.2)$ \\
\hline Pneumonia $^{\mathrm{b}}$ & $34,519(55.1)$ & $78,667(4 \mid . I)$ \\
\hline FEV ${ }_{1}^{\%}$ pred $^{c}$ (most recent) & $67.8 \pm 22.2$ & $93.9 \pm 18.0$ \\
\hline$\geq 80 \%$ pred & 6,573 (28.6) & $3,689(80.1)$ \\
\hline$\geq 50$ to $<80 \%$ pred & II,330 (49.3) & $867(18.8)$ \\
\hline$\geq 30$ to $<50 \%$ pred & $4,264(18.6)$ & $48(1.0)$ \\
\hline$<30 \%$ pred & $818(3.6)$ & $4(0.1)$ \\
\hline FVC \%pred (most recent) & $84.6 \pm 20.7$ & $94.7 \pm 18.6$ \\
\hline Tiffenau index (FEV $/ F V C)$ (most recent) & $65.2 \pm 14.2$ & $80.9 \pm 6.7$ \\
\hline Acute exacerbation of COPD $(<I$ year $)$ & $444(0.7)$ & 0 \\
\hline
\end{tabular}

Notes: Data are presented as mean \pm SD or $n$ (relative \%). alncluding: ischemic

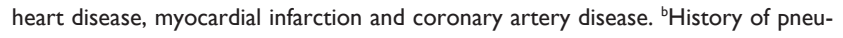
monia $>3$ months prior to index date. ' $\mathrm{COPD} n=22,985$ (36.7\%); matched controls $\mathrm{n}=4,608$ (2.4\%).

Abbreviations: \%pred, percentage of predicted; BMI, body mass index; FEV , forced expiratory volume in I second; FVC, forced vital capacity; ICS, inhaled corticosteroids; LABAs, long-acting beta-2 agonists; LAMAs, long-acting muscarinic antagonists; SABAs, short-acting beta-2 agonists; SAMAs, short-acting muscarinic antagonists.

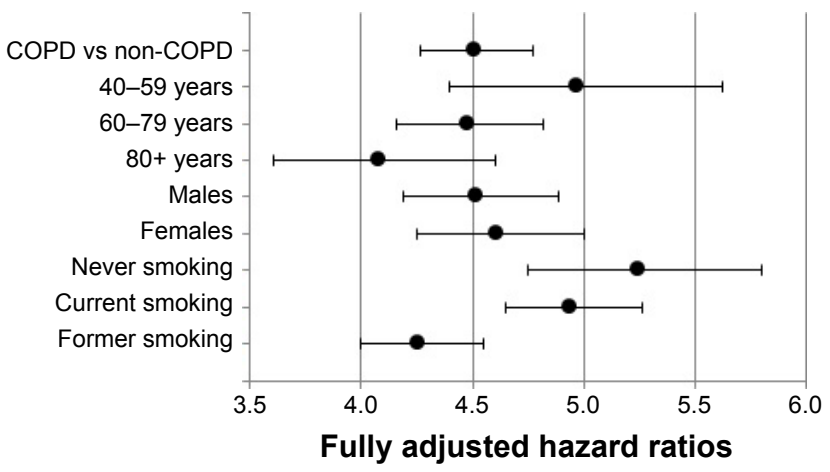

Figure 2 Stratum-specific risk of CAP in patients with COPD compared to matched controls, stratified by age, gender and smoking status.

Notes: Adjusted for age, gender, BMI, antipsychotics, acid suppressants, immunosuppressants, influenza vaccination, pneumococcal vaccination, ICS, coronary artery disease, heart failure, diabetes mellitus, cerebrovascular disease, dementia, malignancy, chronic renal disease, chronic liver disease and smoking status.

Abbreviations: BMI, body mass index; CAP, community-acquired pneumonia; ICS, inhaled corticosteroids.

and female gender. In COPD patients, IR was highest in never smokers (39.51 per 1000 person-years), while former smokers had the lowest IR (28.31 per 1000 person-years). In controls, IR was highest in current smokers (7.82 per 1000 person-years).

\section{CAP risk in COPD patients versus controls}

COPD patients had a fourfold increased CAP risk compared to controls (fully adjusted [adj.] HR 4.51 [4.27-4.77]; Figure 2; Table S4). Stratum-specific CAP risk in COPD was significantly higher (test of interaction HR 1.22 [1.03-1.45]) in younger patients (aged 40-59; fully adj. HR 4.97 [4.40-5.62]), then in elderly patients (aged $\geq 80$; fully adj. HR 4.08 [3.61-4.60]). After stratification to smoking status, the HR of CAP was five times higher in never smoking COPD patients, compared to never smoking controls (fully adj. HR 5.25 [4.75-5.80]). The same for current smoking COPD patients versus current smoking controls (fully adj. HR 4.94 [4.65-5.26]). Former smoking COPD patients had a fourfold increased CAP risk compared to former smoking controls (fully adj. HR 4.26 [4.00-4.55]).

\section{CAP risk and smoking status}

Within COPD, CAP risk in current smokers (fully adj. HR 0.92 [0.82-1.02]) was comparable to the risk in never smokers (reference; Figure 3; Table S5). Former smoking COPD patients had a lower risk (fully adj. HR 0.81 [0.73-0.90]). Current smokers had a significantly higher CAP risk as compared to former smokers $(P<0.001)$. CAP risk increased by older age (fully adj. HR aged 60-79, 2.26 


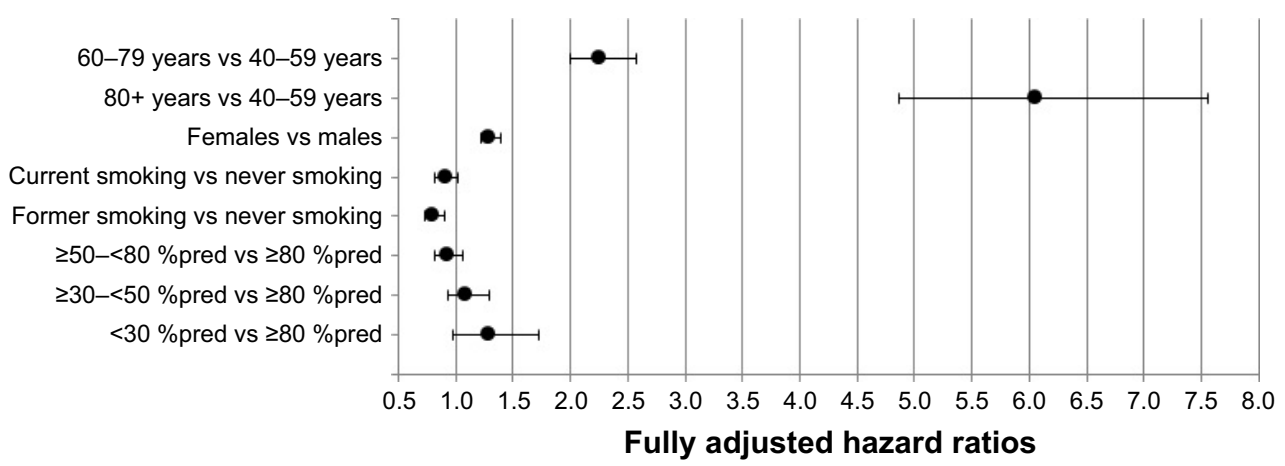

Figure 3 Risk of CAP in patients with COPD, stratified by age, gender, smoking status and the level of airflow obstruction.

Notes: Adjusted for age, gender, BMI, antipsychotics, acid suppressants, immunosuppressants, influenza vaccination, pneumococcal vaccination, ICS, coronary artery disease, heart failure, diabetes mellitus, cerebrovascular disease, dementia, malignancy, chronic renal disease, chronic liver disease and smoking status.

Abbreviations: BMI, body mass index; CAP, community-acquired pneumonia; ICS, inhaled corticosteroids.

[2.00-2.57]; aged $\geq 80,6.06$ [4.86-7.55]) and female gender (fully adj. HR 1.30 [1.22-1.39]). The level of airflow obstruction showed a trend toward increased CAP risk for very severe obstruction (fully adj. HR 1.30 [0.98-1.73]) in comparison to mild obstruction (reference). A subanalysis was performed by smoking status, stratified for level of airflow obstruction (Table S6). No clear trend of increased risk by severity of airflow obstruction was observed within never, current or former smokers.

Within controls, CAP risk was highest in current smokers (fully adj. HR 1.23 [1.13-1.34]), while the risk in former smokers (fully adj. HR 1.07 [0.99-1.16]) was comparable with the risk in never smokers (reference; Table S7). Older age (fully adj. HR aged 60-79 years, 2.54 [2.23-2.90]; aged $\geq 80$ years, 8.85 [7.10-11.00]) and female gender (fully adj. HR 1.26 [1.18-1.35]) showed increased CAP risk.

\section{Discussion}

COPD patients had a fourfold increased CAP risk in comparison with matched controls. Current smoking had no additional impact on CAP risk in COPD. In controls, CAP risk was elevated in current smokers. The risk of CAP increased in both COPD patients and controls with older age and female gender.

\section{CAP risk and IRs}

COPD patients had higher CAP IRs and increased CAP risk compared to controls, in line with former research. ${ }^{4,25}$ The observed IR in COPD patients was higher than reported by Müllerova et $\mathrm{al}^{5}$ (22.4/1000 person-years), but in accordance with the incidence reported by DiSantostefano et al (30.9/1000 person-years). ${ }^{26}$ In controls, Capelastegui et $\mathrm{al}^{27}$ observed an IR of 3.1/1000 adults per year, while our observed IR was twice as high (6.8/1000 person-years).
A possible explanation of the higher IRs observed, might be the rising incidence in European countries. ${ }^{28}$ A number of factors are associated with this phenomenon: populations grow older, and lifestyle factors and comorbid conditions related to CAP become more prevalent. ${ }^{28}$ Older age might also be a potential factor in our study, as the average age was 67 years. This was also shown by Millett et $\mathrm{al}^{29}$ with an incidence of 8.0/1000 person-years in controls $\geq 65$ years old.

Gender differences appeared, as females had a slightly larger CAP risk than males. This is in contrast with former research. ${ }^{2,30,31}$ Reasons for increased risk in females could not be further delineated in this study, but clearly warrant further research. Changes in female lifestyle and risk behavior have been reported in previous decades and might represent important factors. ${ }^{32,33}$ Furthermore, former research showed that respiratory symptoms were more often reported by females than males, ${ }^{34}$ with higher hospitalization incidences in studies concerning milder CAP cases. ${ }^{35,36}$

\section{Smoking status and CAP risk}

Current smoking was associated with increased CAP risk in controls, in line with former research. ${ }^{37-39}$ Smoking has been related to structural changes in the respiratory tract and a decrease in immune response, ${ }^{40}$ which might result in microbial invasion of the bronchial tree, triggering CAP.

In COPD patients, CAP risk was comparable between never and current smokers. It was expected that, in accordance with controls, current smokers were at increased CAP risk. However, Müllerova et $\mathrm{al}^{5}$ also observed no difference in CAP risk between nonsmoking and current smoking COPD patients. Moreover, Myint et $\mathrm{al}^{41}$ observed a larger proportion of current smokers in COPD without CAP than in CAP_COPD. Maybe, inaccurate recording of smoking status by general practitioners influenced the present results, although smoking is 
a QOF indicator, rewarding general practitioners to record patients' smoking status every year when diagnosed with COPD. However, smoking is the major risk factor of COPD, but the majority of persistent smokers do not develop COPD. This suggests that the vulnerability to cigarette smoke varies between individuals. The mechanisms behind this are at the moment not completely understood. ${ }^{42}$ Never smokers may also develop COPD, but by a different pathway than exposure to smoking, ${ }^{43}$ for example, by occupational/environmental exposures, alpha-1-antitrypsin deficiency or due to factors early in life which affect the respiratory health in the long-term. ${ }^{44}$ Pathophysiological differences between subgroups of COPD might contribute to the observed differences in CAP risk. Besides, it is likely that a combination of factors is responsible for disease development, or not. For example, smoking has been associated with CAP development, but is also associated with a lower socioeconomic status, poor diet, alcohol consumption and reduced physical activity, ${ }^{45}$ which, in turn, are also risk factors for CAP. ${ }^{4}$ Furthermore, there are theoretically three general mechanisms related to the increased CAP risk of smoking: 1) tobacco-induced physiological and structural changes, 2) tobacco-induced increase in bacterial virulence, 3 ) tobacco-induced dysregulation of immune function. ${ }^{8}$ These three mechanisms are also key features in COPD, and probably the smoking-effect related to both the development of CAP and COPD, does not sum-up. Overall, many mechanisms might be associated with the observed results, but further research is warranted to explore exact pathways involved.

We also observed no difference concerning severity of airflow obstruction stratified by smoking status and CAP risk. IRs increased with worse airflow obstruction, but only showing a trend toward increased risk in very severe airflow obstruction. Conflicting results were reported before, some observing increased CAP risk in severe and very severe airflow obstruction, ${ }^{46}$ while others observed no difference in CAP risk by airflow obstruction. ${ }^{41}$ There may be reverse causation underlying this lack of relationship; those with worse airflow obstruction stopped smoking, while others continued their smoking habits. However, this is less likely, as smoking status over time was taken into account, correcting for possible confounding. Furthermore, never and current smoking COPD patients had a comparable risk, which stresses the fact that the observed results are not due to smoking cessation.

\section{Strengths and limitations}

The current study includes a large population-based cohort study, providing anonymous longitudinal medical records of primary care patients. ${ }^{12,47}$ This study design makes the current results generalizable to a larger population. In addition, by taking smoking status over time into account, the results are representative of real life setting.

In contrast, several methodological issues could have influenced the results. First, primary care databases rely on the quality of information included in records. ${ }^{12}$ This depends on the accuracy of individuals responsible for entering data. However, inclusion of a large number of patients will minimize potential bias. Second, we did not use spirometry to confirm COPD diagnosis, as this was available for only one-third of patients. Misclassification of exposure is likely to be nondifferential and may have led to a bias toward null. ${ }^{48}$ This implies that the fourfold increased risk of CAP in COPD versus non-COPD may have been underestimated. In addition, CAP diagnosis was not confirmed by chest X-ray, but based on clinical features, probably causing CAP overestimation. ${ }^{49}$ This may have led to a nondifferential misclassification of the outcome and a bias toward the null value. However, it has a small impact on our main findings: the true HR of CAP among smokers versus nonsmokers in COPD would have been lower than the nonsignificant $8 \%$ reduced risk, and will still not support our main hypothesis that smoking increases the risk of CAP in COPD. In addition, ICS use was not separately analyzed, but only included as a potential confounder, as this would go beyond the primary aim of the objective. However, ICS risk in CAP is of high interest, often showing an increased risk, although probably depending on the specific ICS and dose..$^{50}$

\section{Clinical implications}

The results of the present analyses highlight the fact that CAP remains a major health issue, impacting both socially and economically. ${ }^{51}$ Smoking cessation is an important aspect in the management of CAP and especially in control subjects, this strategy might be beneficial and lead to a decreased risk to develop CAP. ${ }^{38}$ In contrast, for patients with COPD, this association seems less clear, but as earlier described, further research is necessary to assess mechanisms associated with the increased risk to develop CAP. For clinical practice it remains important to not underestimate the impact of CAP in patients with COPD. The management of CAP is at the moment focused on treating the disease, and prevention by vaccination, ${ }^{51}$ while prevention of lifestyle factors, such as smoking, alcohol consumption and bodyweight, is at least as important. 4,38,39,52,53

\section{Conclusion}

COPD patients have a fourfold increased risk to develop CAP, independent of smoking status. Identification of factors related with the increased risk of CAP in COPD is warranted, in order to improve the management of patients at risk. 


\section{Acknowledgments}

The abstract of this manuscript was presented as an oral presentation during the conference of the European Respiratory Society in September 2016 in London. The abstract was published in the "ERS International Congress 2016 Abstracts" (http://erj.ersjournals.com/content/48/suppl 60/ $\underline{\mathrm{OA} 1504)}$.

\section{Disclosure}

The authors report no conflicts of interest in this work.

\section{References}

1. Herrero FS, Olivas JB. Microbiology and Risk Factors for Communityacquired Pneumonia. Semin Respir Crit Care Med. 2012;33(3): 220-231.

2. Vila-Corcoles A, Ochoa-Gondar O, Rodriguez-Blanco T, Raga-Luria X, Gomez-Bertomeu F; Group ES. Epidemiology of community-acquired pneumonia in older adults: a population-based study. Respir Med. 2009;103(2):309-316.

3. Lim WS, Baudouin SV, George RC, et al. BTS guidelines for the management of community acquired pneumonia in adults: update 2009 . Thorax. 2009;64(Suppl 3):iii1-iii55.

4. Torres A, Peetermans WE, Viegi G, Blasi F. Risk factors for communityacquired pneumonia in adults in Europe: a literature review. Thorax 2013;68(11):1057-1065.

5. Müllerova H, Chigbo C, Hagan GW, et al. The natural history of community-acquired pneumonia in COPD patients: a population database analysis. Respir Med. 2012;106(8):1124-1133.

6. Braeken DCW, Franssen FME, Schuette H, et al. Increased severity and mortality of CAP in COPD: results from the German Competence Network, CAPNETZ. Chronic Obstr Pulm Dis. 2015;2(2): $131-140$.

7. Molinos L, Clemente MG, Miranda B, et al; ASTURPAR Group. Community-acquired pneumonia in patients with and without chronic obstructive pulmonary disease. J Infect. 2009;58(6):417-424.

8. Bagaitkar J, Demuth DR, Scott DA. Tobacco use increases susceptibility to bacterial infection. Tob Induc Dis. 2008;4:12.

9. Bauer CM, Morissette MC, Stampfli MR. The influence of cigarette smoking on viral infections: translating bench science to impact COPD pathogenesis and acute exacerbations of COPD clinically. Chest. 2013;143(1):196-206.

10. van Eerd EAM, van Rossem CR, Spigt MG, Wesseling G, van Schayck OCP, Kotz D. Do we need tailored smoking cessation interventions for smokers with COPD? A comparative study of smokers with and without COPD regarding factors associated with tobacco smoking. Respiration. 2015;90(3):211-219.

11. Getsios D, Marton JP, Revankar N, et al. Smoking cessation treatment and outcomes patterns simulation: a new framework for evaluating the potential health and economic impact of smoking cessation interventions. Pharmacoeconomics. 2013;31(9):767-780.

12. Herrett E, Gallagher AM, Bhaskaran K, et al. Data resource profile: Clinical Practice Research Datalink (CPRD). Int J Epidemiol. 2015; 44(3):827-836.

13. Roland M. Linking physicians' pay to the quality of care - a major experiment in the United kingdom. $N$ Engl J Med. 2004;351(14): $1448-1454$.

14. Wvan der Zanden R, de Vries F, Lalmohamed A, et al. Use of dipeptidylpeptidase- 4 inhibitors and the risk of pneumonia: a population-based cohort study. PLoS One. 2015;10(10):e0139367.

15. Millett ER, De Stavola BL, Quint JK, Smeeth L, Thomas SL. Risk factors for hospital admission in the 28 days following a community-acquired pneumonia diagnosis in older adults, and their contribution to increasing hospitalisation rates over time: a cohort study. BMJ Open. 2015; 5(12):e008737.
16. Mullerova H, Shukla A, Hawkins A, Quint J. Risk factors for acute exacerbations of COPD in a primary care population: a retrospective observational cohort study. BMJ Open. 2014;4(12):e006171.

17. Garcia Rodriguez LA, Wallander MA, Tolosa LB, Johansson S. Chronic obstructive pulmonary disease in UK primary care: incidence and risk factors. COPD. 2009;6(5):369-379.

18. de Vries F, Setakis E, Zhang B, van Staa TP. Long-acting \{beta\}2agonists in adult asthma and the pattern of risk of death and severe asthma outcomes: a study using the GPRD. Eur Respir J. 2010;36(3): 494-502.

19. Zhang B, de Vries F, Setakis E, van Staa TP. The pattern of risk of myocardial infarction in patients taking asthma medication: a study with the general practice research database. J Hypertens. 2009;27(7): $1485-1492$.

20. Herrett E, Thomas SL, Schoonen WM, Smeeth L, Hall AJ. Validation and validity of diagnoses in the general practice research database: a systematic review. Br J Clin Pharmacol. 2010;69(1):4-14.

21. Global Initiative for Chronic Obstructive Lung Disease. Global strategy for the diagnosis, management, and prevention of Chronic Obstructive Pulmonary Disease. 2015; Available from: http://www.goldcopd.org/ guidelines-global-strategy-for-diagnosis-management.html. Accessed February 17, 2015.

22. Booth HP, Prevost AT, Gulliford MC. Validity of smoking prevalence estimates from primary care electronic health records compared with national population survey data for England, 2007 to 2011. Pharmacoepidemiol Drug Saf. 2013;22(12):1357-1361.

23. de Vries F, van Staa TP, Bracke MS, Cooper C, Leufkens HG, Lammers JW. Severity of obstructive airway disease and risk of osteoporotic fracture. Eur Respir J. 2005;25(5):879-884.

24. Altman DG, Bland JM. Interaction revisited: the difference between two estimates. BMJ. 2003;326(7382):219.

25. Ryan M, Suaya JA, Chapman JD, Stason WB, Shepard DS, Thomas CP. Incidence and cost of pneumonia in older adults with COPD in the United States. PLoS One. 2013;8(10):e75887.

26. DiSantostefano RL, Sampson T, Le HV, Hinds D, Davis KJ, Bakerly ND. Risk of pneumonia with inhaled corticosteroid versus long-acting bronchodilator regimens in chronic obstructive pulmonary disease: a new-user cohort study. PLoS One. 2014;9(5):e97149.

27. Capelastegui A, Espana PP, Bilbao A, et al. Study of communityacquired pneumonia: incidence, patterns of care, and outcomes in primary and hospital care. J Infect. 2010;61(5):364-371.

28. Thomsen RW, Riis A, Norgaard M, et al. Rising incidence and persistently high mortality of hospitalized pneumonia: a 10-year populationbased study in Denmark. J Intern Med. 2006;259(4):410-417.

29. Millett ER, Quint JK, Smeeth L, Daniel RM, Thomas SL. Incidence of community-acquired lower respiratory tract infections and pneumonia among older adults in the United Kingdom: a population-based study. PLoS One. 2013;8(9):e75131.

30. Gutierrez F, Masia M, Mirete C, et al. The influence of age and gender on the population-based incidence of community-acquired pneumonia caused by different microbial pathogens. $J$ Infect. 2006;53(3): 166-174.

31. Mannino DM, Davis KJ, Kiri VA. Chronic obstructive pulmonary disease and hospitalizations for pneumonia in a US cohort. Respir Med. 2009;103(2):224-229.

32. Raho E, van Oostrom SH, Visser M, et al. Generation shifts in smoking over 20 years in two Dutch population-based cohorts aged 20-100 years. BMC Public Health. 2015;15:142.

33. Bilal U, Beltran P, Fernandez E, Navas-Acien A, Bolumar F, Franco M. Gender equality and smoking: a theory-driven approach to smoking gender differences in Spain. Tob Control. 2016;25(3):295-300.

34. Lamprecht B, Vanfleteren LE, Studnicka M, et al. Sex-related differences in respiratory symptoms: results from the BOLD Study. Eur Respir J. 2013;42(3):858-860.

35. Marrie TJ, Huang JQ. Low-risk patients admitted with communityacquired pneumonia. Am J Med. 2005;118(12):1357-1363.

36. Aliyu ZY, Aliyu MH, McCormick K. Determinants for hospitalization in "low-risk" community acquired pneumonia. BMC Infect Dis. 2003;3:11. 
37. Almirall J, Bolibar I, Serra-Prat M, et al. New evidence of risk factors for community-acquired pneumonia: a population-based study. Eur Respir J. 2008;31(6):1274-1284.

38. Almirall J, Gonzalez CA, Balanzo X, Bolibar I. Proportion of community-acquired pneumonia cases attributable to tobacco smoking. Chest. 1999;116(2):375-379.

39. Baik I, Curhan GC, Rimm EB, Bendich A, Willett WC, Fawzi WW. A prospective study of age and lifestyle factors in relation to community-acquired pneumonia in US men and women. Arch Intern Med. 2000;160(20):3082-3088.

40. Arcavi L, Benowitz NL. Cigarette smoking and infection. Arch Intern Med. 2004;164(20):2206-2216.

41. Myint PK, Lowe D, Stone RA, Buckingham RJ, Roberts CM. UK National COPD Resources and Outcomes Project 2008: patients with chronic obstructive pulmonary disease exacerbations who present with radiological pneumonia have worse outcome compared to those with non-pneumonic chronic obstructive pulmonary disease exacerbations. Respiration. 2011;82(4):320-327.

42. Pan Z, Yu H, Liao JL. Probing cellular and molecular mechanisms of cigarette smoke-induced immune response in the progression of chronic obstructive pulmonary disease using multiscale network modeling. PLoS One. 2016;11(9):e0163192.

43. Salvi SS, Barnes PJ. Chronic obstructive pulmonary disease in nonsmokers. Lancet. 2009;374(9691):733-743.

44. Carraro S, Scheltema N, Bont L, Baraldi E. Early-life origins of chronic respiratory diseases: understanding and promoting healthy ageing. Eur Respir J. 2014;44(6):1682-1696.
45. Almirall J, Blanquer J, Bello S. Community-acquired pneumonia among smokers. Arch Bronconeumol. 2014;50(6):250-254.

46. Crim C, Calverley PM, Anderson JA, et al. Pneumonia risk in COPD patients receiving inhaled corticosteroids alone or in combination: TORCH study results. Eur Res J. 2009;34(3):641-647.

47. Clinical Practice Research Datalink. Available from: http://www.cprd. com. Accessed January 20, 2016.

48. Rothman KJ, Greenland S, Lash TL. Modern Epidemiology. Lippincott Williams and Wilkins; Philadelphia: Lippincott Williams \& Wilkins; 2008:137-144.

49. Mandell LA, Wunderink RG, Anzueto A, et al. Infectious Diseases Society of America/American Thoracic Society consensus guidelines on the management of community-acquired pneumonia in adults. Clin Infect Dis. 2007;44(Supp1 2):S27-S72.

50. Finney L, Berry M, Singanayagam A, Elkin SL, Johnston SL, Mallia P. Inhaled corticosteroids and pneumonia in chronic obstructive pulmonary disease. Lancet Respir Med. 2014;2(11):919-932.

51. Welte T, Torres A, Nathwani D. Clinical and economic burden of community-acquired pneumonia among adults in Europe. Thorax. 2012;67(1):71-79.

52. Grau I, Ardanuy C, Calatayud L, Schulze MH, Linares J, Pallares R. Smoking and alcohol abuse are the most preventable risk factors for invasive pneumonia and other pneumococcal infections. Int $J$ Infect Dis. 2014;25:59-64.

53. Cecere LM, Williams EC, Sun H, et al. Smoking cessation and the risk of hospitalization for pneumonia. Respir Med. 2012;106(7):1055-1062.
International Journal of COPD

\section{Publish your work in this journal}

The International Journal of COPD is an international, peer-reviewed journal of therapeutics and pharmacology focusing on concise rapid reporting of clinical studies and reviews in COPD. Special focus is given to the pathophysiological processes underlying the disease, intervention programs, patient focused education, and self management protocols.

\section{Dovepress}

This journal is indexed on PubMed Central, MedLine and CAS. The manuscript management system is completely online and includes a very quick and fair peer-review system, which is all easy to use. Visit $\mathrm{http} / / / \mathrm{www}$.dovepress.com/testimonials.php to read real quotes from published authors. 